\section{Vol. 29, Issue 6, June 2006}

Editorials

243 Is Mastectomy Still Justified - And if, in Which Patients?

Audretsch, W.; Andree, C. (Düsseldorf)

246 Correlation of ErbB2 Gene Status, mRNA and Protein Expression

D'Incalci, M. (Milan)

Original Articles

249 Correlation of ErbB2 Gene Status, mRNA and Protein Expression in a Panel of $>\mathbf{1 0 0}$ Human Tumor Xenografts of Different Origin

Kuesters, S.; Maurer, M. (Freiburg i.Br.); Burger, A.M. (Baltimore, MD); Metz, T.; Fiebig, H.H. (Freiburg i.Br.)

258 Sensitivity Analysis of Costs Factors for Various Therapy Options in the Treatment of Follicular Lymphoma

Schmitz, S.; Aly, F.; Steinmetz, H.; Diehl, V.; Rehwald, U. (Köln)

267 Management of Skin-Sparing Mastectomy: Results of a Survey of German Hospitals

Dian, D. (München); Hemminger, G. (Hamburg); Janni, W.; Friese, K. (München); Jänicke, F. (Hamburg)

Case Reports

273 Safe Use of Oxaliplatin in a Patient with Metastatic Breast Cancer and Combined Renal and Hepatic Failure

Honecker, F.U.; Brümmendorf, T.H.; Klein, O.; Bokemeyer, C. (Hamburg)

276 Classical and Atypical Location of Adamantinomas Presentation of Two Cases

Ulmar, B. (Ulm); Delling, G.; Werner, M. (Hamburg); Huch, K.; Reichel, H. (Ulm)

Review Article

281 Virtual Colonoscopy: An Overview Lefere, P.; Gryspeerdt, S.; Schotte, K. (Roeselare)

\section{Band 29, Heft 6, Juni 2006}

Editorials

243 Ist Mastektomie noch gerechtfertigt - und wenn ja, bei welchen Patientinnen?

Audretsch, W.; Andree, C. (Düsseldorf)

246 Korrelation von ErbB2 Genstatus, mRNA- und Proteinexpression

D'Incalci, M. (Milan)

Originalarbeiten

249 Korrelation von ErbB2 Genstatus, mRNA- und Proteinexpression in über 100 humanen Tumorxenografts verschiedener Ursprungsgewebe Kuesters, S.; Maurer, M. (Freiburg i.Br.); Burger, A.M. (Baltimore, MD); Metz, T.; Fiebig, H.H. (Freiburg i.Br.)

258 Analyse von Kostenfaktoren für unterschiedliche Therapieoptionen bei der Behandlung follikulärer Lymphome

Schmitz, S.; Aly, F.; Steinmetz, H.; Diehl, V.; Rehwald, U. (Köln)

267 Management der hautsparenden Mastektomie: Ergebnisse einer Umfrage unter deutschen Krankenhäusern

Dian, D. (München); Hemminger, G. (Hamburg); Janni, W.; Friese, K. (München); Jänicke, F. (Hamburg)

Kasuistiken

273 Sicherer Einsatz von Oxaliplatin bei einer Patientin mit metastasiertem Mammakarzinom und kombiniertem Leber-/Nierenversagen Honecker, F.U.; Brümmendorf, T.H.; Klein, O.; Bokemeyer, C. (Hamburg)

276 Klassische und atypische Lokalisation von Adamantinomen - zwei Falldarstellungen Ulmar, B. (Ulm); Delling, G.; Werner, M. (Hamburg); Huch, K.; Reichel, H. (Ulm)

Übersichtsarbeit

281 Virtuelle Kolonoskopie: Übersicht Lefere, P.; Gryspeerdt, S.; Schotte, K. (Roeselare)

\begin{tabular}{ll}
\hline KARGER & @ 2006 S. Karger GmbH, Freiburg \\
Fax +497614520714 & Artikel (Volltext) und Inhaltsverzeichnisse \\
$\begin{array}{l}\text { E-mail Information@Karger.de } \\
\text { www.karger.com }\end{array}$ & sowie das vorläufige Inhaltsverzeichnis des nächsten Heftes: \\
www.karger.com/onk_bk.htm
\end{tabular}


Vol. 29, Issue 6, June 2006

Reports of Oncological Societies

288 Chirurgische Arbeitsgemeinschaft Onkologie (CAO-V) der Deutschen Gesellschaft für Viszeralchirurgie

290 PharmaForum

292 PharmaNews / PharmaTicker

265 Imprint

296 Meetings and Conferences

298 Guidelines for Authors

Forthcoming papers are listed on page 300 .

\section{Band 29, Heft 6, Juni 2006}

Mitteilungen onkologischer Gesellschaften

288 Chirurgische Arbeitsgemeinschaft Onkologie (CAO-V) der Deutschen Gesellschaft für Viszeralchirurgie

290 PharmaForum

292 PharmaNews / PharmaTicker

265 Impressum

296 Tagungen und Kongresse

299 Hinweise für Autoren

Einen Ausblick auf den Inhalt der kommenden Hefte finden Sie auf Seite 300.

\section{KARGER}

Fax +497614520714

E-mail Information@Karger.de www.karger.com (c) 2006 S. Karger GmbH, Freiburg 